University of Wollongong

Research Online

Australian Institute for Innovative Materials -

Papers

Australian Institute for Innovative Materials

$1-1-2015$

\title{
Functionalised inherently conducting polymers as low biofouling materials
}

Binbin Zhang

University of Wollongong, binbinz@uow.edu.au

Alexander Nagle

University of Wollongong, arn734@uowmail.edu.au

Gordon G. Wallace

University of Wollongong, gwallace@uow.edu.au

Timothy W. Hanks

Furman University, tim.hanks@furman.edu

Paul J. Molino

University of Wollongong, pmolino@uow.edu.au

Follow this and additional works at: https://ro.uow.edu.au/aiimpapers

Part of the Engineering Commons, and the Physical Sciences and Mathematics Commons

Research Online is the open access institutional repository for the University of Wollongong. For further information contact the UOW Library: research-pubs@uow.edu.au 


\title{
Functionalised inherently conducting polymers as low biofouling materials
}

\author{
Abstract \\ Diatoms are a major component of microbial biofouling layers that develop on man-made surfaces \\ placed in aquatic environments, resulting in significant economic and environmental impacts. This paper \\ describes surface functionalisation of the inherently conducting polymers (ICPs) polypyrrole (PPy) and \\ polyaniline (PANI) with poly(ethylene glycol) (PEG) and their efficacy as fouling resistant materials. Their \\ ability to resist interactions with the model protein bovine serum albumin (BSA) was tested using a quartz \\ crystal microbalance with dissipation monitoring (QCM-D). The capacity of the ICP-PEG materials to \\ prevent settlement and colonisation of the fouling diatom Amphora coffeaeformis (Cleve) was also \\ assayed. Variations were demonstrated in the dopants used during ICP polymerisation, along with the \\ PEG molecular weight, and the ICP-PEG reaction conditions, all playing a role in guiding the eventual \\ fouling resistant properties of the materials. Optimised ICP-PEG materials resulted in a significant \\ reduction in BSA adsorption, and $>98 \%$ reduction in diatom adhesion. \\ Keywords \\ conducting, materials, inherently, biofouling, functionalised, low, polymers \\ Disciplines \\ Engineering | Physical Sciences and Mathematics

\section{Publication Details} \\ Zhang, B., Nagle, A. R., Wallace, G. G., Hanks, T. W. \& Molino, P. J. (2015). Functionalised inherently \\ conducting polymers as low biofouling materials. Biofouling: the journal of bioadhesion and biofilm \\ research, 31 (6), 493-502.
}




\section{Functionalised inherently conducting polymers}

\section{as low biofouling materials}

Binbin Zhang ${ }^{1}$, Alex R. Nagle ${ }^{1}$, Gordon G. Wallace ${ }^{1}$, Timothy W. Hanks ${ }^{3 *}$, and Paul J. Molino $^{1,2 *}$

${ }^{1}$ ARC Centre of Excellence for Electromaterials Science, ${ }^{2}$ ARC Research Hub for Australian Steel Manufacturing, Intelligent Polymer Research Institute, University of Wollongong, Wollongong, Australia.

${ }^{3}$ Department of Chemistry, Furman University, USA

*Author for correspondence: Prof Timothy Hanks, tim.hanks@furman.edu; tel.: +1 864294 3373; fax: +1 864294 2056; Dr Paul J Molino, pmolino@uow.edu.au; tel.; (+61) 242981449; fax: (+61) 42213114

Word count:

Text: 5564

References: 814

Figures: 10

Tables: 51 


\begin{abstract}
Diatoms are a major component of microbial biofouling layers that develop on man-made surfaces placed in aquatic environments, resulting in significant economic and environmental impacts. Herein we describe the surface functionalisation of the inherently conducting polymers (ICPs) polypyrrole (PPy) and polyaniline (PANI) with poly(ethylene glycol) (PEG) and their efficacy as fouling resistant materials. Their ability to resist interactions with the model protein bovine serum albumin (BSA) was tested using quartz crystal microbalance with dissipation monitoring (QCM-D). The ICP-PEG materials capacity to prevent settlement and colonisation of the biofouling diatom Amphora coffeaeformis (Cleve) was also assayed. We demonstrate that variations in the dopants used during ICP polymerisation, the PEG molecular weight, and the ICP-PEG reaction conditions, all play a role in guiding the eventual fouling resistant properties of the materials. Optimised ICP-PEG materials resulted in a significant reduction in BSA adsorption, and $>98 \%$ reduction in diatom adhesion.
\end{abstract}

Keywords: polypyrrole; polyaniline; conducting polymer; poly(ethylene glycol); biofouling; diatom. 


\section{Introduction}

The accumulation of organic matter and organisms on man-made surfaces is commonly termed biofouling. Biofouling is a major problem for all artificial surfaces immersed in aquatic environments, where the development of microbial and macrofouling layers poses a considerable challenge for a range of diverse activities. For example, the adhesion of microbial slimes and macrofouling organisms is enormously problematic for watercraft, where a slime layer of just $1 \mathrm{~mm}$ in thickness can significantly increase the skin friction and hydrodynamic drag of a ship (Lewthwaite et al. 1985; Schultz 2005; Schultz 2007). It is estimated that 90\% of the world's trade is currently transported via maritime shipping, where biofouling has been shown to increase propulsive fuel costs by up to $30 \%$ (Brady 2000). The cost of biofouling to the shipping transport industry worldwide (excluding expenses associated with hull cleaning, repainting and corrosion) is on the order of several billion dollars annually.

Marine coatings designed to resist the adhesion and growth of biofouling layers have generally been engineered to be either toxic to biofouling organisms (antifouling coatings), or to promote their release from the coating surface when the adhered organisms are impacted by hydrodynamic forces (fouling release coatings). While fouling release coatings have proven successful against most animal and macrofouling species, they are not particularly effective against microbial slime layers that are composed predominately of bacteria and diatoms (Cassé and Swain 2006; Hunsucker et al. 2014, Molino et al. 2009a; Molino et al. 2009b, Zargiel and Swain 2014), nor do they work well with slow moving vessels or stationary structures.

A suite of green surface chemistries are now being explored to prevent the initial adhesion of organic conditioning layers and biofouling by microbial and macrofouling organisms (Krishnan et al. 2008, Zhang et al. 2009, Callow and Callow 2011). These chemistries are primarily based on presenting either highly hydrophobic or hydrophilic interfaces, or alternatively, presenting a surface that is decorated by molecules that present both hydrophilic 
and hydrophobic functional groups (ie amphiphilic surfaces). Highly hydrophilic surface chemistries, such as ethylene glycols and a variety of zwitterionic compounds have been explored for use as low fouling surface chemistries. Ethylene glycol (EG) based systems have been comprehensively studied, with a range of properties such as chain length, surface grafting density and molecular weight all investigated to determine their influence on resisting protein and cellular interactions (Jeon et al. 1991, Jeon and Andrade 1991, Kingshott et al. 2002). EG and short chain oligo-ethylene glycols are generally accepted to resist protein and cellular adhesion through the high hydration of tightly packed surface bound chains, preventing interactions with the foulant and access to the underlying substratum. Higher molecular weight poly(ethylene glycol) (PEG) combine both high hydration with conformational flexibility to provide a steric barrier preventing surface adsorption. Steric repulsion evolves from a configurational enthalpy loss upon compression of the PEG chain on approach of a protein, reducing the total number of conformations available to the polymer chain (Lee et al. 1989, Chen et al. 2010). PEG modified model surfaces in particular have been widely demonstrated to reduce adhesion of a number of marine fouling organisms (Aldred et al. 2010; Bauer et al. 2014; Schilp et al. 2007; Schilp et al. 2009).

Inherently conducting polymers (ICPs), such as polypyrrole (PPy) and polyaniline (PANI), are under active investigation as coating materials for metals exposed to aqueous environments due to their ability to reduce corrosion (Biallozor and Kupniewska 2005). Like biofouling, corrosion is an enormous problem in a host of industries, with costs to the U.S. estimated at more than 3\% of the GDP ( $\$ 276$ billion in 1998) (NACE International 2002). These problems are not unrelated, as biofouling organisms themselves can generate corrosion (e.g. sulfate reducing bacteria), or lead to degradation of coatings, which in turn, can initiate corrosion. PANI has previously been demonstrated to exhibit modest inherent antifouling properties against marine organisms (Yang et al. 2009), and has been used as a conductive filler to generate hypochlorous acid $(\mathrm{HOCl})$ via electrolysis as a mechanism to prevent fouling of the coating surface (Chen et al. 2012). 
We have shown that PANI and PPy react readily with hydrophobic thiols to give surfaces with dramatically decreased surface energies (Bergman and Hanks 2000) and more recently, we demonstrated that ICPs can be modified to resist adhesion by biological systems (Molino et al. 2012; Molino et al. 2013). PPy doped with the bioactive polyanion dextran sulphate was modified by reaction with thiol-terminated poly(ethylene glycol) to generate a biomaterial that displayed a reduction in protein and cell binding as compared to the un-functionalised polymer surface (Molino et al. 2013). Herein we expand upon these observations by investigating the efficacy of grafting PEG to PPy and PANI films doped with anions better suited for deployment in marine coatings. We also examine the effects of PEG molecular weight and grafting reaction conditions by testing the PEG functionalised films against adsorption by the model protein bovine serum albumin (BSA) and the known marine fouling diatom Amphora coffeaeformis (Cleve).

\section{Materials and Methods}

\section{$2.1 \quad$ General}

Pyrrole and aniline monomer were purified by distillation and stored at $-18^{\circ} \mathrm{C}$. Potassium chloride $(\mathrm{KCl})$, dodecylebenzenesulfonic acid (DBSA), di-sodium hydrogen orthophosphate, phosphate buffered saline (PBS) and bovine serum albumin (BSA) were purchased from Sigma-Aldrich (Sydney, Australia). Poly(ethylene glycol) methyl ether thiol (PEG-SH) with two different molecular weight (5k and 40k Da) were purchased from Jenkem (USA). Deionised water was purified using a Millipore Ultrapure water purification system. All other reagents were purchased from commercial houses and used as received.

\subsection{Electrochemical Polymerisation of PPy and PANI Films}

Electrochemical polymerisation of PPy and PANI films for quartz crystal microbalance with dissipation monitoring (QCM-D) experiments were performed using a Q-Sense Electrochemistry Module (QEM 401) axial flow cell with a Q-Sense E4 Quartz Crystal 
Microbalance system (Q-Sense AB, Västra, Frölunda, Sweden). The QCM-D sensor was an A-T cut quartz crystal with a $10 \mathrm{~mm}$ diameter gold electrode (QSX301) with a fundamental resonance frequency of $5 \mathrm{MHz}$ (Q-Sense AB, Västra, Frölunda, Sweden). Prior to polymer polymerisation, the electrode surface was cleaned with piranha solution ( $7: 3$ concentrated sulphuric acid to $30 \%$ hydrogen peroxide) for 3 mins, rinsed thoroughly with deionised (DI) water, and dried under a stream of nitrogen gas. Aqueous solutions containing either $0.2 \mathrm{M}$ pyrrole, or $0.01 \mathrm{M}$ aniline, with $2 \mathrm{mg} / \mathrm{ml} \mathrm{DBSA}$ or $0.25 \mathrm{M} \mathrm{KCl}$ as the counterions, were used during electrochemical polymerisation (Wallace et al. 2002). The PPy and PANI films were galvanostatically grown onto the gold QCM-D sensors. The galvanostat consisted of an eDAQ e-corder 410 recorder and EA163 potentiostat that was coupled to the Q-Sense electrochemistry flow cell. The aqueous monomer/counterion solutions were passed through the axial flow cell at a rate of $60 \mu \mathrm{l} / \mathrm{min}$, during which a current density of $0.25 \mathrm{~mA} / \mathrm{cm}^{2}$ was applied for all polymer films to a total charge density of $0.03 \mathrm{C} / \mathrm{cm}^{2}$. Following electropolymerisation, the quartz electrodes deposited with the PPy or PANI films were removed from the axial flow cell, washed with DI water, and dried under a flow of nitrogen gas.

\subsection{PEG Modification}

PEG-thiol adsorption experiments were performed on the Q-Sense E4 QCM-D using standard Q-Sense flow modules (QFM 401). Previously we have demonstrated aqueous solvents to result in enhanced PEG-SH binding to ICPs, compared to ethanol, and thus aqueous solvents have been employed in this study (Molino et al. 2013). QCM-D sensors supporting PPy and PANI films were placed in a standard flow module and equilibrated in either DI water or disodium hydrogen orthophosphate buffer ( $\mathrm{pH}$ 9) under a constant flow of $10 \mu \mathrm{l} / \mathrm{min}$ at $25 \pm 0.02^{\circ} \mathrm{C}$ until the QCM-D measurement parameters stabilised. Thereafter a $0.1 \mathrm{mM}$ solution of either 5k or 40k PEG-SH in the relevant solvent was introduced into the flow chamber at 
$10 \mu \mathrm{l} / \mathrm{min}$ for $60 \mathrm{mins}$, followed by rinsing with fresh solvent without PEG-SH at the same flow rate until the $f$ and $D$ QCM-D parameters stabilised. All experiments were run in triplicate.

\section{$2.4 \quad$ Protein Adsorption Experiments}

Protein adsorption experiments were performed using the Q-Sense E4 QCM-D system with the standard Q-sense flow modules. QCM-D sensors deposited with PPy or PANI films, either with or without PEG-SH modification, were placed in the flow modules and allowed to equilibrate in PBS solution ( $\mathrm{pH}$ 7.4) for at least 60 mins at $22 \pm 0.02^{\circ} \mathrm{C}$ until the $f$ and $D$ measurement parameters stabilised. Thereafter a $50 \mu \mathrm{g} / \mathrm{ml}$ solution of bovine serum albumin (BSA) was introduced into the flow chamber at $10 \mu \mathrm{l} / \mathrm{min}$ for $60 \mathrm{mins}$, and then rinsed with fresh PBS at a rate of $10 \mu \mathrm{l} / \mathrm{min}$ until the QCM-D measurement parameters stabilised. All experiments were run in triplicate.

\section{$2.5 \quad$ Cell Culture and Adhesion Experiments}

Amphora coffeaeformis (Cleve) was a kind gift from Assoc Prof Richard Wetherbee (Botany Department, The University of Melbourne). Cells were cultured in $50 \mathrm{ml}$ Greiner Bio-One plastic tissue culture flasks at room temperature in sterile f/2 medium under Silvania $18 \mathrm{~W}$ GroLux and Crompton Lighting Fluorescent lamps with a daily 14:10 light/dark cycle. To prevent bacterial contamination during experiments, cells destined for use were transferred to a separate $50 \mathrm{ml}$ culture dish with flasks containing $\mathrm{f} / 2$ medium with $0.1 \mathrm{mg} / \mathrm{ml}$ streptomycin sulphate and 100 units $/ \mathrm{ml}$ sodium penicillin for the duration of $24 \mathrm{hrs}$.

Thereafter cells were harvested from tissue culture flasks by applying light pressure with a disposable plastic pipette. Medium containing dislodged cells was transferred to a $15 \mathrm{ml}$ sterile plastic test tube and pelleted using a Thermoscientific Heraeus Multifuge IS-R centrifuge at $1500 \mathrm{rpm}$ for 1 minute, the supernatant decanted off and fresh $\mathrm{f} / 2$ sterile medium added to the flask. Cells were redispersed in fresh $\mathrm{f} / 2$ medium up to the desired concentration. 
PANI and PPy films were electrochemically polymerised at a rate of $0.25 \mathrm{~mA} / \mathrm{cm}^{2}$ for $2 \mathrm{mins}$ on gold-coated mylar. The electrochemical cell used for polymerization consisted of a platinum wire counter electrode, a $\mathrm{Ag} \mid \mathrm{AgCl}$ reference electrode, and the gold mylar as the working electrode. Small discs were cut from the polymer coated Mylar sheet, which were then functionalised by incubating the samples in the various PEG-SH solutions following the same conditions as described in section 2.3 , followed by rinsing with DI water.

For cell adhesion experiments, polymer coated electrodes with, or without, PEG-SH functionalization were incubated in sterile $\mathrm{f} / 2$ medium for $2 \mathrm{hrs}$ in a 96 well tissue culture plate. Thereafter, A. coffeaeformis cells were seeded onto the polymer samples at a concentration of 15,000 cells $/ \mathrm{cm}^{2}$. The samples were then left under normal incubation conditions for $24 \mathrm{hrs}$. Thereafter the samples were removed from the culture plate, gently dipped in sterile $f / 2$ medium to remove weakly adhered cells, and fixed/stained in $\mathrm{f} / 2$ medium with $2.5 \%$ glutaraldehyde and $20 \mu \mathrm{g} / \mathrm{ml}$ Hoechst 33342 (trihydrochloride) (Molecular probes: H1399) for 10 mins. Samples were then rinsed with sterile $\mathrm{f} / 2$ medium and fluorescent images were obtained using a Zeiss AxioImager fluorescence microscope with a mercury bulb light source. The number of cells per image was quantified using Image $J^{\circledR}$ image analysis software.

\subsection{Characterisation}

\subsubsection{Atomic Force Microscopy}

The morphology of the polymer film surfaces were explored using a JPK Nanowizard II AFM (JPK Instruments AG, Germany). Images were obtained in air using intermittent contact mode AFM with a Nanoworld silica nitride cantilever (spring constant $40 \mathrm{~N} / \mathrm{m}$ ). Image scan of $5 \mu \mathrm{m} \times 5 \mu \mathrm{m}$ were obtained at a scan rate of $1 \mathrm{~Hz}$. Roughness values and total surface area measurements were calculated using SPM Image Processing software V.3 (JPK Instruments AG, Germany) and Gwyddion SPM software (version 2.34). 


\subsubsection{Water Contact Angle Measurements}

The mean static water contact angle measurements were performed using a DataPhysics optical contact angle goniometer. At least three measurements were undertaken on three separate films using DI water droplets of $2 \mu 1$ for each reported value.

\subsubsection{QCM Data Analysis}

The Q-tools software package v.3.0.10.286 (Biolin Sci, AB) was used to apply the Voigt model to determine the mass $\left(\mathrm{ng} / \mathrm{cm}^{2}\right)$ of PEG-SH and protein adsorbed to the modified sensor surface. Specific model input parameters for PEG-SH binding and protein adsorption quantification include layer density $\left(\left(1027 \mathrm{~kg} / \mathrm{m}^{3}-\mathrm{PEG}-\mathrm{SH}\right),\left(1150 \mathrm{~kg} / \mathrm{m}^{3}-\mathrm{BSA}\right)\right)$, fluid density $\left(1020 \mathrm{~kg} / \mathrm{m}^{3}\right)$, layer viscosity $\left(1^{-6} \leq 1^{-2} \mathrm{~kg} / \mathrm{ms}\right)$, layer shear modulus $\left(1^{4} \leq 1^{7} \mathrm{~Pa}\right)$, and mass $\left(115 \leq 1.15^{5} \mathrm{ng} / \mathrm{cm}^{2}\right)$. The $5^{\text {th }}, 7^{\text {th }}$ and $9^{\text {th }}$ overtones were used for all modelling calculations.

\section{$2.7 \quad$ Statistical Analyses}

All statistical analyses were performed using Minitab 17 statistical software. Statistically significant differences were determined using one way ANOVA with Tukey's multiple comparison test, with a $95 \%$ confidence interval.

\section{Results}

\subsection{Polymer Characterisation}

Electrochemical polymerisation of PPy and PANI films was performed galvanostatically, with homogenous films deposited onto the gold electrode on the QCM-D sensor for all monomer/dopant combinations. PANI films displayed rougher surfaces than PPy films, with PANI-Cl showing the greatest $\mathrm{R}_{R M S}$ roughness (Table 1). Static water contact angle measurements revealed that PPy and PANI doped with DBSA had the most hydrophobic surfaces, followed by PPy-Cl and PANI-Cl (Table 1). However all polymer surfaces exhibited 
relatively low surface energies, with mean static water contact angle measurements falling within $\sim 14^{\circ}$.

\subsection{PEG-SH Modification of films measured using QCM-D}

Surface modification of PPy and PANI was performed using two different molecular weights of PEG-SH (5k and 40k) in either DI water or in aqueous media buffered to $\mathrm{pH} 9$ with disodium hydrogen orthophosphate (Figure 2). The reaction with 40k PEG-SH consistently resulted in an overall larger mass deposition on the film surface than that with 5k PEG-SH. There was also a general trend of more PEG-SH binding to PPy films as compared to PANI films under the same reaction conditions. The presence of buffer generally had little effect on the total mass change, except for PPy-DBSA modified with 40k PEG-SH ( $<<0.001)$, and PPy$\mathrm{Cl}(\mathrm{P}<0.042)$ and PANI-DBSA $(\mathrm{P}<0.015)$ modified with the 5k PEG-SH.

The mechanical properties, or conformation, of the covalently attached PEG-thiol layer can be investigated by studying the ratio between the two QCM-D parameters, the frequency $(f)$ and dissipation $(D)$ (ie $\Delta D / \Delta f$ plot). Larger $\Delta D / \Delta f$ ratios represent a more viscoelastic, hydrated adlayer on the sensor surface, while smaller ratios are indicative of more dehydrated, rigid surface coatings (Höök et al. 1998; Molino et al. 2013,). Not surprisingly, the longer PEG chains showed greater dissipation of the QCM resonance energy as would be expected for highly hydrated, extended chains (Figure 2c). There was no significant difference between the surface structures of the PEG layers deposited in DI water or in buffer solution, except for PPyDBSA $(\mathrm{P}<0.037)$ and PANI-DBSA $(\mathrm{P}<0.000)$ modified with 40k PEG-SH. 


\subsection{QCM-D Protein Resistance to PEG Modified Polymers}

BSA was employed as a model protein through which to determine the ability for the PEG-SH modified polymers to resist protein interactions. BSA adsorption was significantly reduced on all films modified with PEG-SH as compared to the control films $(\mathrm{p}<0.05)$ (Figure 3). For all monomer/dopant combinations, the greatest resistance to BSA adsorption was seen when employing the 40k PEG-SH surface modification. The 5K PEG-SH modification significantly reduced BSA adsorption on the PPy films under all surface modification conditions $(\mathrm{p}<0.05)$, but was less effective for PANI where mean BSA adsorption was higher than that of PPy. In general, the PPy films reacted with PEG-SH in pH 9 buffer demonstrated less BSA adsorption reduction than those reacted in DI water, though the differences were not statistically significant, with all films illustrating low protein adsorption compared to the controls. PANI demonstrated greater sensitivity to the $\mathrm{pH}$ buffer. In most cases, BSA adsorption was equal to or greater on films modified in this medium. The $\mathrm{pH}$ influence on the polymer and PEG-SH reaction on subsequent protein resistance was stronger for the 40k PEG-SH than the 5k.

\subsection{Cell Adhesion Assays of Amphora coffeaeformis binding to PEG-thiol Modified Polymers}

The ability for the PEG-SH modified PPy and PANI surfaces to resist marine microbial diatom attachment was tested using the fouling diatom A. coffeaeformis. A. coffeaeformis is a highly successful fouler of both toxic biocidal antifouling coatings, and more modern low surface energy hydrophobic fouling release coatings. Cell adhesion assays were conducted over a $24 \mathrm{hr}$ period without mechanical agitation of the media surrounding the samples. Figure 4 illustrates the cell adhesion results of $A$. coffeaeformis to PPy and PANI control (Figure 4a) and PEG-SH modified (Figure 4b, c) polymer surfaces. Cell adhesion was comparable among all PPy and PANI control films without PEG-SH modification. Films modified with the 5k PEG-SH showed no significant difference in cell adhesion relative to the control films except for PPy 
and PANI doped with DBSA and reacted with the PEG-SH in $\mathrm{pH} 9$ buffer $(\mathrm{p}<0.000)$ (Figure 4, 5). PPy-DBSA and PANI-DBSA modified at $\mathrm{pH} 9$ demonstrated a reduction of $>99 \%$ compared to the control films. Conversely, PEG-SH modification of all PPy and PANI films with 40k PEG-SH resulted in a significant reduction in cell adhesion compared to control films under all reaction conditions (Figure 4) $(\mathrm{p}<0.05)$. All polymer films modified with 40k PEG$\mathrm{SH}$ in either DI water or $\mathrm{pH} 9$ demonstrated a reduction in cellular adhesion of $>98 \%$ with minimal cellular adhesion $\left(<12\right.$ cells $\left./ \mathrm{mm}^{2}\right)$, except PPy-Cl and PANI-DBSA modified with 40k PEG-SH in DI water (152 \pm 83 and $124 \pm 12$ cells $/ \mathrm{mm}^{2}$, respectively).

\section{Discussion}

ICPs are of interest to the marine coatings industry due to their ability to reduce corrosion of metal surfaces. We have previously shown that PPy grown with the polysaccharide biodopant dextran sulphate could be made to resist the adsorption of the extracellular matrix binding protein fibronectin as well as primary mouse myoblasts through a reaction with PEG-SH (Molino et al. 2013). In this study we extend our investigation to include PANI, the ICP most frequently investigated for anti-corrosion applications, and to dopants that are more amenable to the marine environment. The $\mathrm{Cl}^{-}$ion is inexpensive and ubiquitous, while DBSA has been widely used to make ICPs dispersible in organic solvents; a feature that may be useful in practical coating systems. These surfaces are challenged with the model protein BSA and the adhesion of the troublesome marine biofouling diatom A. coffeaeformis.

\subsection{Polymer properties and PEG-SH modification}

The PPy and PANI films were electrochemically grown under conditions such that they possessed relatively low surface roughness and surface energies with comparable values (Figure 1, Table 1). This insured that morphological features of the films would have a minimal impact on the fouling experiments. 
In our earlier work, we showed that the molecular weight of the PEG-SH (1k, 5k, 20k, 40k Da) used to modify PPy/DS was an important factor in controlling protein adsorption to the polymer surface. The increase in protein resistance with increasing PEG molecular weight was attributed to an increase in PEG layer thickness, providing a more effective steric barrier between the solution and the ICP interface. Herein we chose the 5k and 40k PEG-SH to investigate the influence of the molecular weight on these new platform polymers. The QCMD measurement of PEG-SH modification in DI water demonstrated a higher amount of 40k PEG-SH binding to the polymer surface than the 5k PEG-SH under the same reaction conditions, which was due primarily to the larger molecular weight. However, the mass difference was less than the actual molecular weight ratio difference $(40 \mathrm{k}: 5 \mathrm{k}=8: 1)$, indicating that the binding density for 40k PEG-SH was lower than the 5k PEG-SH. This was likely due to the steric congestion from the longer chain length and larger molecular volume. It was also noted that with the same PEG-SH molecular weight, the increase of mass deposition resulted in a reduction in the $D / f$ ratio, indicating the increase in binding density resulting in reduced hydration of the PEG-SH chains.

The PEG-SH modification in $\mathrm{pH} 9$ buffer was more complex than in the DI water, attributed to the ion rich environment, which made it difficult to compare with the QCM-D measurements obtained in DI water. QCM-D measures of mass binding to the ICP surface include contributions from both the PEG-SH and solvent coupled with the adhered PEG, as well as ion movement. The reaction of PEG-SH to ICP results in a reduction in the degree of conjugation of the ICP backbone (Molino et al. 2013). During reduction, the mobile dopants in the ICP move out of the polymer, while the immobile dopants attract the ions from the surrounding solution, which will both cause measureable changes in polymer mass as well as the dissipation measurement. The QCM-D detected mass change on the polymer surface in $\mathrm{pH} 9$ demonstrated a different trend between the $\mathrm{Cl}^{-}$and DBSA doped polymers compared with those in DI water. 
However, in general, the 40k PEG-SH binding was higher than the 5k PEG-SH, with a relatively higher $D / f$ ratio, which corresponded with the modification in DI water.

\subsection{Reduction of protein adsorption}

Both the surface density and molecular weight of PEG have been demonstrated to be critical for allowing PEG functionalised surfaces to resist interactions with a range of proteins (Harder et al. 1998; Herrwerth et al. 2003; Kingshott et al. 2002; Ngadi et al. 2008; Sofia et al. 1998). As with our previous work on preventing the adsorption of fibronectin on PPy-DS, the surface modification of these PPy and PANI films with PEG-SH dramatically reduced BSA adsorption. While an increase in PEG-SH molecular weight from $5 \mathrm{k}$ to $40 \mathrm{k}$ provided an overall reduction in BSA adsorption, the influence of $\mathrm{pH}$ on the efficacy of the PEG-SH adlayer was less clear. The ICP films modified in DI water demonstrated BSA resistance consistent with the mass of PEG-SH, that is, the $\mathrm{Cl}^{-}$doped ICPs with more PEG-SH deposition displayed less protein adsorption as compared to the DBSA doped ICPs. The PEG modification in $\mathrm{pH} 9$ improved the PPy films capability to resist BSA adsorption, which was consistent with our previous work with PPy-DS (Molino et al. 2013).

The PANI films were more sensitive to the PEG-SH molecular weight, with the difference between BSA binding to the films as a function of molecular weight greater than that observed for PPy. The PEG grafting density and surface coverage has been shown to be critical to the protein resisting properties of the PEG adlayer (Kingshott et al. 2002; Sofia et al. 1998). The lower mass deposition of PEG on PANI compared to PPy (Figure 2) could have resulted in insufficient coverage of the underlying substratum, allowing the protein to manoeuvre between the PEG chains and adsorb to the surface. However, an increased chain length of PEG has been shown to enhance the protein resistance by improving the amount of PEG on the surface and increasing the exclusion distance between the protein and the underlying substratum (Kingshott et al. 2002). Therefore the PANI films modified with 40k PEG-SH were less affected by the 
lower grafting density, and demonstrated comparable reduction to BSA adsorption. Unlike the PPy films, PANI films modified at $\mathrm{pH} 9$ displayed compromised protein resistance as compared to the modification in DI water, despite the fact that similar amounts of PEG-SH were deposited and the similarity of the organisation of the adlayer as evidenced by the $D / f$ ratio. A possible explanation for this is the acidic PANI was largely deprotonated in the basic buffer solution, leading to a relatively hydrophobic substratum. Along with the lower density of chains anchored to the film surface, this may have provided additional areas for BSA adsorption.

\subsection{Reduction of marine fouling diatom adsorption}

Ethylene glycol (EG) oligomers and polymers have been widely investigated for their ability to resist marine microbial adhesion and biofilm formation upon functionalised surfaces (Schilp et al. 2007; Schilp et al. 2009). Here the surface modification of the PPy and PANI films with the 40k PEG significantly reduced the adhesion of the biofouling diatom A. coffeaeformis to the polymer surface. While an increase in the steric exclusion zone and overall surface coverage of the surface tethered PEG explain the success of the 40k PEG-SH, compared to the 5k MW PEG molecules, the dramatic reduction in cell binding on both PPy and PANI doped with DBSA and treated with 5k PEG-SH under basic conditions is surprising and quite different from the BSA adsorption. The ICP interface is a mosaic of the polymer and dopant rich areas, with the resulting physicochemical and topographical properties of the interface significantly influenced by the nature of the dopant molecule. Both the spatial distribution of the dopant, and its physicochemical properties, may act to guide the nature of the PEG-SH binding and organisation on the surface (Gelmi et al. 2012). DBSA is a poorly water-soluble surfactant that possesses a hydrocarbon chain and a hydrophilic sulfonic acid group. Whereas the small soluble chloride ion can easily exchange with ions in the buffer solution or be expelled to balance the film charge upon any deprotonation events, the DBSA will be reluctant to leave, 
possibly decreasing the film acidity or requiring the cations to be imported into the film on deprotonation. Thus, exposure to the buffer solution may result in some restructuring of the film surfaces. The DBSA dopant may influence the nature of the PEG-SH binding to the ICP backbone, and/or the structure of the PEG on the surface. Further investigations are required to elucidate the exact mechanism/s driving the observed fouling resistant properties for these particular polymeric systems.

\section{Conclusion}

Surface functionalised ICPs have for the first time been applied to generate surfaces capable of resisting the adhesion of marine biofouling diatoms. PPy and PANI films doped with the synthetic dopant $\mathrm{Cl}^{-}$and DBSA modified with PEG-SH of differing molecular weights were demonstrated to resist interactions with the protein BSA and the common biofouling diatom $A$. coffeaeformis. The capacity for the PPy and PANI films to resist BSA and A. coffeaformis interactions were enhanced with the higher molecular weight PEG-SH. Diatom adhesion was reduced by $>98 \%$ for both ICPs when reacted with the 40k PEG-SH except for PPy-Cl and PANI-DBSA, where A. coffeaeformis binding was reduced by $82 \%$ and $86 \%$ when functionalised by PEG-SH in DI water, respectively. ICPs are a highly flexible material platform which are a promising material for aquatic antifouling applications. Their highly tailorable surface and bulk chemistry, in conjunction with their inherent anticorrosive properties and amenability to large scale synthesis and fabrication techniques relevant to industry, make them ideal candidate materials for use as ultra-low fouling coatings for a range of aquatic applications. The potential to engage specific state-of-the-art material processing and fabrication technologies such as wetspinning, electrospinning, extrusion and 3D printing, provides further opportunities to develop these materials for niche applications such as filtration and particle separation, with exploitation of their electrochemical properties allowing their use in areas such as low fouling electrodes and electrochemical environmental sensing. 


\section{Acknowledgments}

TWH thanks the Australian-American Fulbright Commission for a scholarship supporting this work. GGW thanks the Australian Research Council for funding through his Australian Laureate Fellowship. PJM acknowledges funding support through the Vice Chancellors Fellowship award (UOW). We also acknowledge the Australian National Nanofabrication Facility (ANFF) for access to equipment.

Aldred N, Li G, Gao Y, Clare AS, Jiang S. 2010. Modulation of barnacle (Balanus amphitrite Darwin) cyprid settlement behavior by sulfobetaine and carboxybetaine methacrylate polymer coatings. Biofouling. 26:673-683.

Bauer S, Alles M, Finlay JA, Callow JA, Callow ME, Rosenhahn A. 2014. Influence of zwitterionic SAMs on protein adsorption and the attachment of algal cells. J Biomater Sci Polym Ed. 25:1530-1539.

Bergman B, Hanks TW. 2000. Spectroscopic, microscopic, and surface analysis of alkanethioland fluoroalkanethiol-modified conducting polymer thin films. Macromolecules. 33:8035-8042.

Biallozor S, Kupniewska A. 2005. Conducting polymers electrodeposited on active metals. Synth Met. 155:443-449.

Brady R. 2000. Clean hulls without poisons: devising and testing nontoxic marine coatings. J Coat Tech. 72:45-56.

Callow JA, Callow ME. 2011. Trends in the development of environmentally friendly foulingresistant marine coatings. Nat Comm 2: 244.

Cassé F, Swain GW. 2006. The development of microfouling on four commercial antifouling coatings under static and dynamic immersion. Int Biodeterior Biodegrad 57:179-185.

Chen S, Li L, Zhao C, Zheng J. 2010. Surface hydration: Principles and applications toward low-fouling/nonfouling biomaterials. Polymer 51: 5283 - 5293.

Chen S, Zhu J, Zhou T, He B, Huang W, Wang B. 2012. Preparation and properties study of polyaniline conductive anti-fouling coatings. Int J Electrochem Sci. 7:8170. 
Gelmi A, Higgins MJ, Wallace GG. 2012. Attractive and repulsive interactions originating from lateral nanometer variations in surface charge/energy of hyalurnic acid and chondroitin sulfate doped polypyrrole observed using atomic force microscopy. J Phys Chem B. 116: 13498.

Harder P, Grunze M, Dahint R, Whitesides GM, Laibinis PE. 1998. Molecular conformation in oligo(ethylene glycol)-terminated self-assembled monolayers on gold and silver surfaces determines their ability to resist protein adsorption. J Phys Chem B. 102:426436.

Herrwerth S, Eck W, Reinhardt S, Grunze M. 2003. Factors that determine the protein resistance of oligoether self-assembled monolayers-internal hydrophilicity, terminal hydrophilicity, and lateral packing density. J Am Chem Soc. 125:9359-9366.

Höök F, Rodahl M, Brzezinski P, Kasemo B. 1998. Energy dissipation kinetics for protein and antibody-antigen adsorption under shear oscillation on a quartz crystal microbalance. Langmuir, 14:729-734.

Hunsucker KZ, Koka A, Lund G, Swain G. 2014. Diatom community structure on in-service cruise ship hulls. Biofouling. 30:1133-1140.

Jeon SI, Andrade JD. 1991. Protein surface interactions in the presence of polyethylene oxide: II effect of protein size. J Colloid Interface Sci. 142:159-166.

Jeon SI, Lee JH, Andrade JD, De Gennes PG. 1991. Protein surface interactions in the presence of polyethylene oxide: I simplified theory. J Colloid Interface Sci. 142:149-158.

Kingshott P, Thissen H, Griesser HJ. 2002. Effects of cloud-point grafting, chain length, and density of PEG layers on competitive adsorption of ocular proteins. Biomaterials. 23:2043-2056.

Krishnan S, Weinman CJ, Ober CK. Advances in polymers for anti-biofouling surfaces. J Mat Chem. 18, $3405-3413$.

Lee JH, Kopecek J, Andrade JD. 1989. Protein-resistant surfaces prepared by PEO-containing block copolymer surfactants. J Biomed Mater Res. 23:351-368.

Lewthwaite JC, Molland AF, Thomas KW. 1985. An investigation into the variation of the skin frictional resistance with fouling. Royal Institution of Naval Architects Transactions. 127:16.

Molino PJ, Campbell E, Wetherbee R. 2009a. Development of the initial diatom microfouling layer on antifouling and fouling-release surfaces in temperate and tropical Australia. Biofouling. 25:685-694. 
Molino PJ., Childs S, Eason Hubbard, MR, Carey, JM, Burgman, MA, Wetherbee, R. 2009b. Development of the primary bacterial microfouling layer on antifouling and fouling release coatings in temperate and tropical environments in Eastern Australia. Biofouling. 25:149-162.

Molino PJ, Wallace GG, Hanks TW. 2012. Hydrophobic conducting polymer films from post deposition thiol exposure. Synth Met. 162:1464-1470.

Molino PJ, Zhang B, Wallace GG, Hanks TW. 2013. Surface modification of polypyrrole/biopolymer composites for controlled protein and cellular adhesion. Biofouling. 29:1155-1167.

NACE International. 2002. Corrosion costs and preventive strategies in the United States. In: National Technical Information Service. http://www.nace.org/Publications/Cost-ofCorrosion-Study/\#sthash.3dJ2VBBL.dpuf

Ngadi N, Abrahamson J, Fee C, Morison K. 2008. QCM-D study on the relationship of PEG coated stainless steel surfaces to protein resistance. Interanational Journal of Chemical and Biological Engineering. 1:125-129.

Schilp S, Kueller A, Rosenhahn A, Grunze M, Pettitt ME, Callow ME, Callow JA. 2007. Settlement and adhesion of algal cells to hexa(ethylene glycol)-containing selfassembled monolayers with systematically changed wetting properties. Biointerphases. 2:143-150.

Schilp S, Rosenhahn A, Pettitt ME, Bowen J, Callow ME, Callow JA, Grunze M. 2009. Physicochemical properties of (ethylene glycol)-containing self-assembled monolayers relevant for protein and algal cell resistance. Langmuir. 25:10077-10082.

Schultz MP. 2005. Frictional resistance of antifouling coating systems. J Fluids Eng. 126:10391047.

Schultz MP. 2007. Effects of coating roughness and biofouling on ship resistance and powering. Biofouling. 23:331-341.

Sofia SJ, Premnath V, Merrill EW. 1998. Poly(ethylene oxide) grafted to silicon surfaces: grafting density and protein adsorption. Macromolecules. 31:5059-5070.

Wallace GG, Teasdale PR, Spinks GM, Kane-Maguire LAP. 2002. Conductive electroactive polymers: intelligent materials systems. CRC Press.

Yang SC, Brown R, Ramotowski T, Tucker W, Maranda L, Chena R, Shen M. 2009. New anti fouling coatings based on conductive polymers. University of Rhode Island, Kingston. 
Zargiel KA, Swain GW. 2014. Static vs dynamic settlement and adhesion of diatoms to ship hull coatings. Biofouling. 30:115-129.

Zhang Z, Finlay JA, Wang L, Gao Y, Callow JA, Callow ME, Jiang S. 2009. Polysulfobetainegrafted surfaces for environmentally benign ultralow fouling marine coatings. Langmuir. 25(23): 13516 - 13521.

\section{Figure and Table Captions}

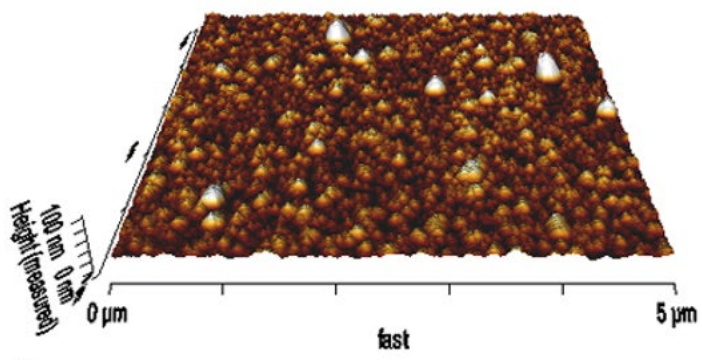

a.

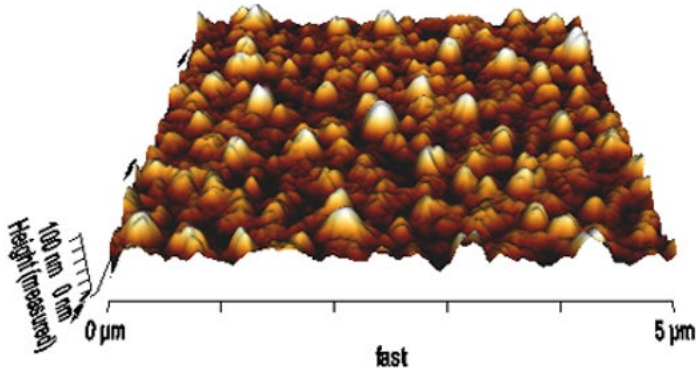

C.

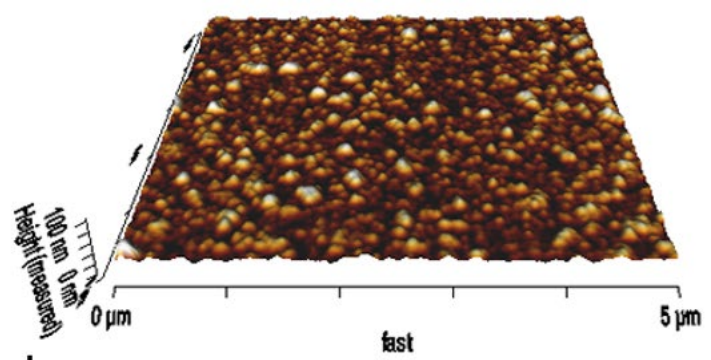

b.

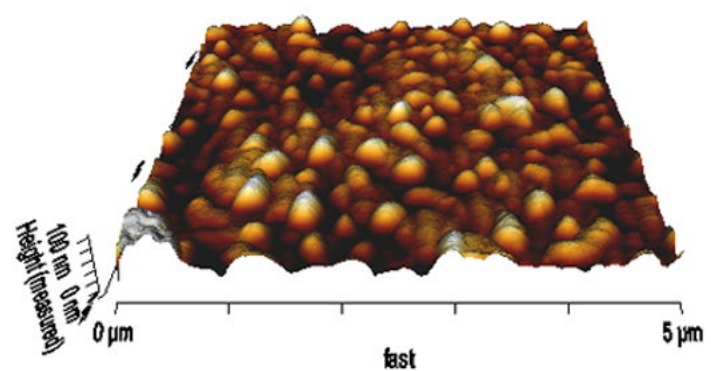

d.

Figure 1. Representative AFM 3D topographic images ( $5 \mu \mathrm{m} \times 5 \mu \mathrm{m})$ of PPy-Cl (a), PPy-DBSA (b), PANI-Cl (c) and PANI-DBSA (d). 


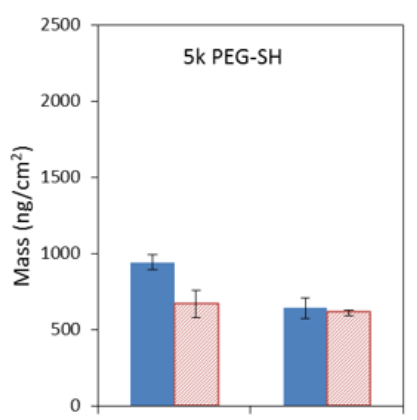

a.

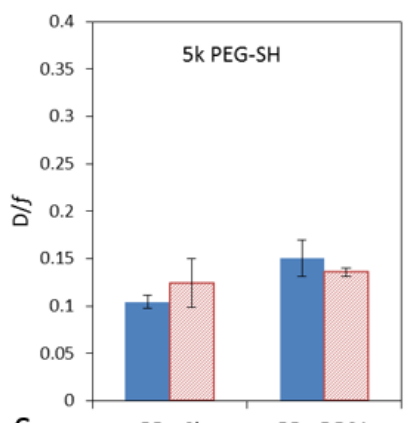

C.

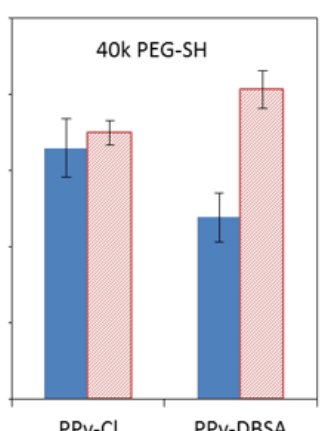

PPy-Cl PPy-DBSA

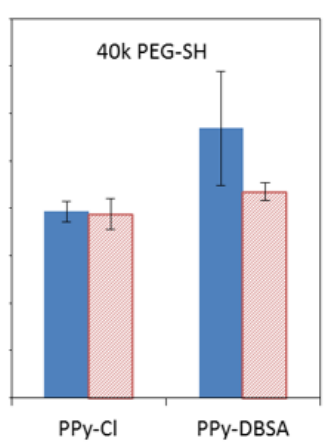

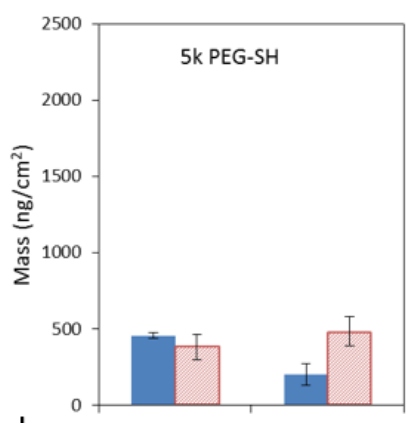

b.

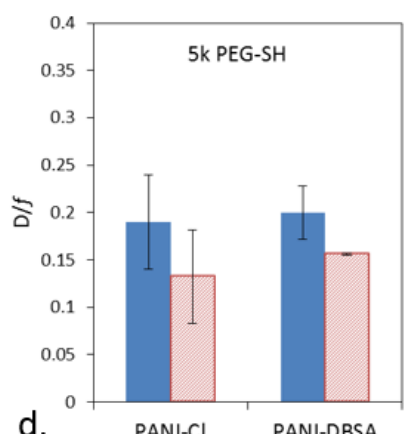

d.
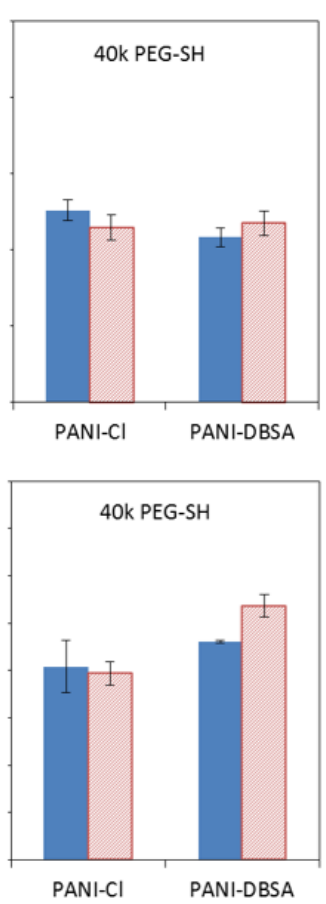

Figure 2. QCM-D measurements of the adsorption and the mechanical signature (D/f) of PPy ((a) and (c), respectively) and PANI ((b) and (d), respectively) polymers reacted with either 5k or 40k PEG-SH. Solid filled (blue) bars represent the reactions in DI water, and the striped filled (red) bars represent the reactions in $\mathrm{pH} 9$ buffer. All error bars are representative of $95 \%$ confidence intervals around the mean.

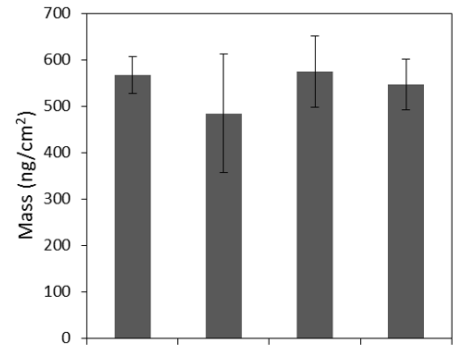

a.

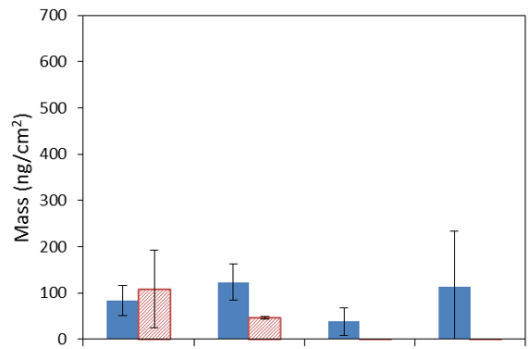

b.

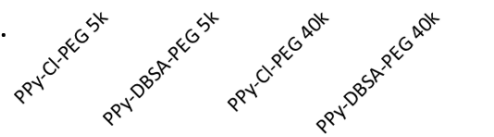

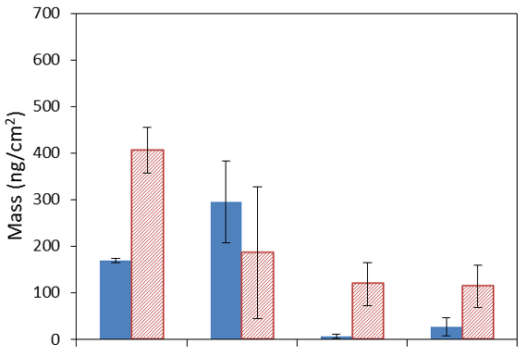

c.

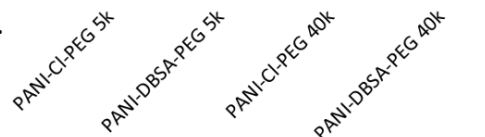

Figure 3. Adsorption of BSA to PANI and PPy control films (a), PEG-SH modified PPy films (b), and PEG-SH modified PANI films (c). PEG-SH modification was performed either in DI water (solid blue) or at pH 9 (striped red). Error bars represent 95\% confidence intervals around the mean. 

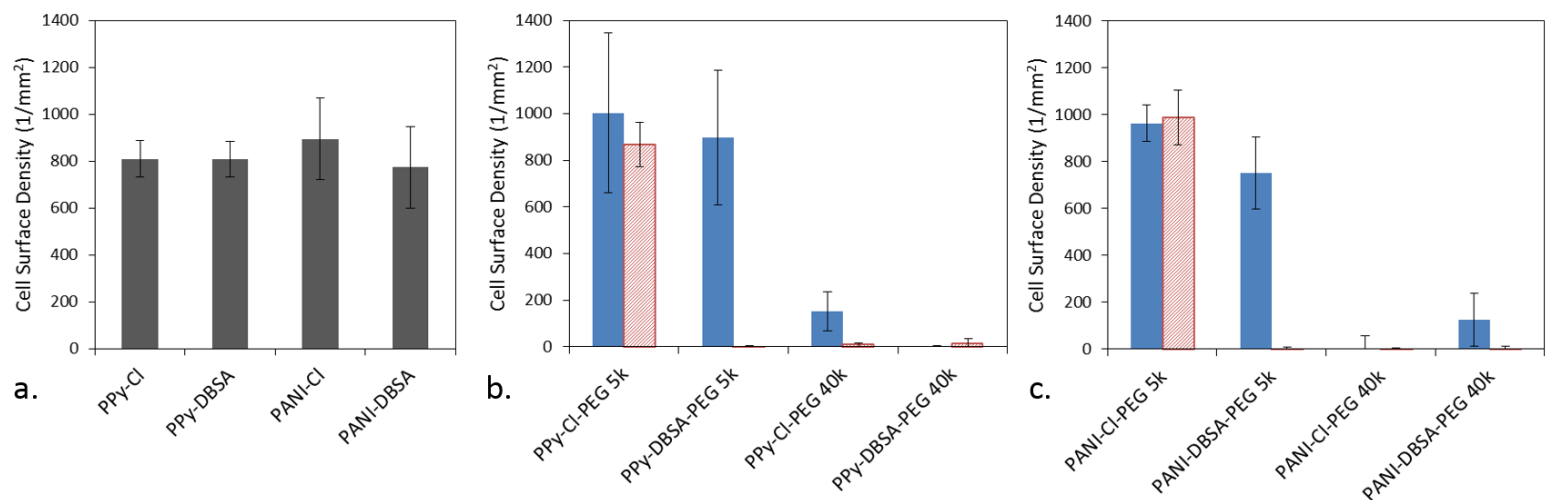

Figure 4. Adhesion of $A$. coffeaeformis cells to PANI and PPy control films (a), PEG-SH modified PPy films (b), and PEG-SH modified PANI films (c). PEG-SH modification was performed either in DI water (solid blue) or at pH 9 (striped red). Error bars represent 95\% confidence intervals around the mean.

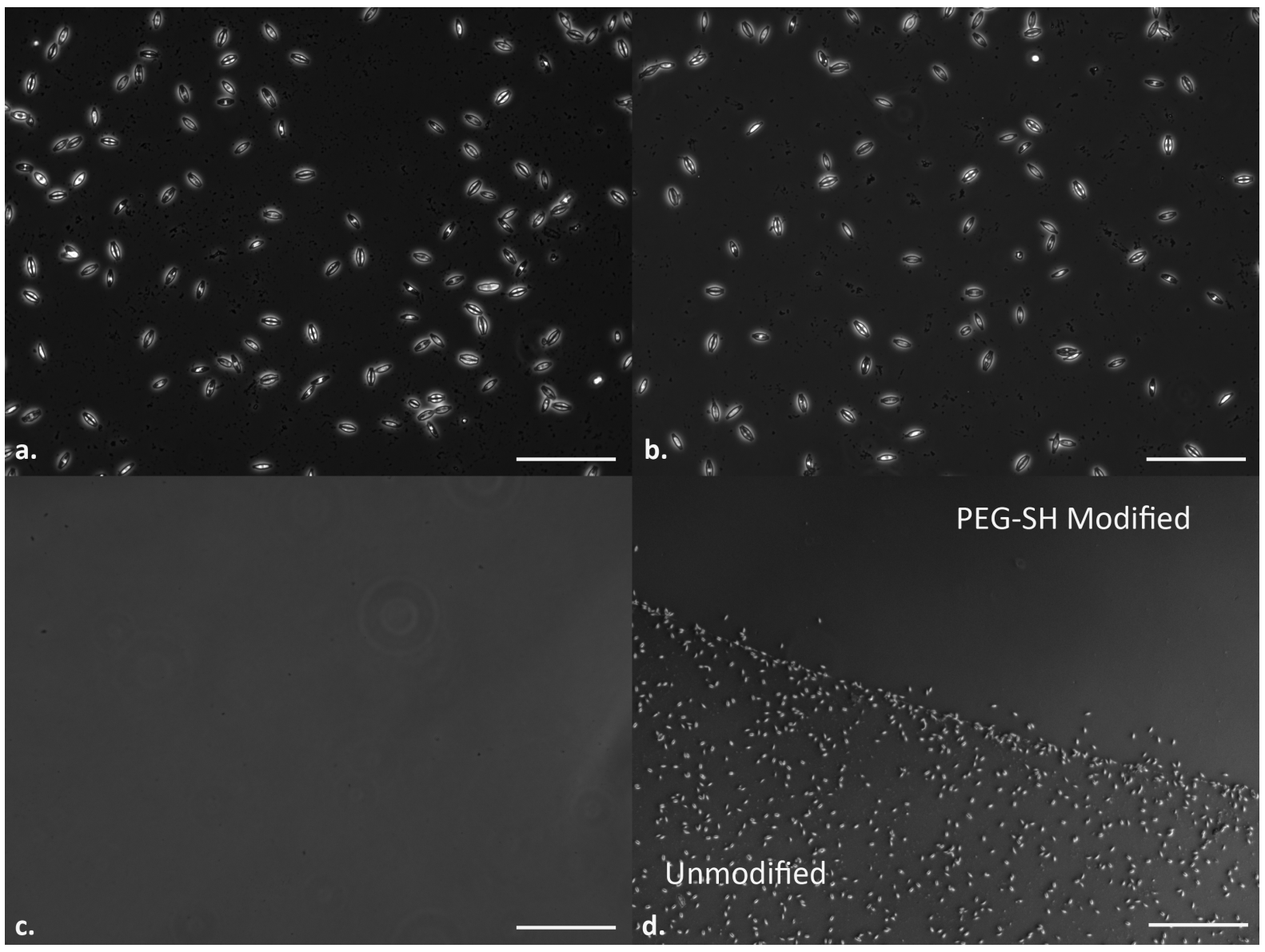

Figure 5. Representative light microscopy images of $A$. coffeaeformis cells adhered to the PPy/DBSA unmodified Control (a), or functionalised with 5k PEG-SH in either DI (b) or in buffer at pH 9 (c). (d) A. coffeaeformis cells on PPy/DBSA modified with 40k PEG-SH in buffer at $\mathrm{pH} 9$. Half the film was immersed and modified with 
PEG-SH, with a clear boundary delineating the PEG-SH functionalised polymer region (top) from the unmodified area allowing cell adhesion (bottom). Scale bars: a-c: $100 \mu \mathrm{m}$; d: $400 \mu \mathrm{m}$. 